\title{
De Re Essentialism, Species, and Modal Ambiguity
}

\author{
Ross D. Inman \\ University of Notre Dame \\ Center for Philosophy of Religion
}

Forthcoming in Metaphysica

As far as philosophical trends go, de re essentialism-the view that objects have essential properties and must have such properties in order to exist-has fallen out of fashion with a great many contemporary philosophers of biology. And by the lights of some philosophers of biology, analytic metaphysicians with de re essentialist leanings such as Saul Kripke, Hillary Putnam, and David Wiggins along with their more recent progeny have yet to get the memo. What might explain this apparent disconnect between modal metaphysics and recent work in the philosophy of biology?

According to Samir Okasha (2002: 192), we can put our money on one of the following three explanations of this disconnect: either (i) ignorance of developments in modern biology, (ii) ignorance of contemporary metaphysics, or (iii) different concepts of essentialism at work in each domain. Both Joseph LaPorte (2009) and Samir Okasha (2002) contend that in so far as all prominent species concepts in biology undermine the view that organisms essentially belong to their species, (i) is the most probable explanation when it comes to the continued vitality of such a view among contemporary metaphysicians in the last three decades. ${ }^{1}$ In the words of LaPorte (2009: 56), "essentialists have simply been uninformed about systematics." My aim here is to show how a recurring argument against the application of de re essentialism in the biological domain reveals the exact opposite, and that in the particular case at hand (ii) is the more likely candidate when it comes to explaining at least one exaggerated report of the demise of de re biological essentialism.

\footnotetext{
${ }^{1}$ See LaPorte (1997) for the source of this objection to de re biological essentialism, which is then restated and endorsed by Okasha (2002), and defended once more by LaPorte (2009).
} 
We start with a de re essentialist gloss on biological species-membership, a view that LaPorte and Okasha attribute to a host of contemporary metaphysicians but whose philosophical lineage, of course, traces back to Aristotle. $^{2}$ Since Okasha isolates the essentialist notion of species-membership in the thought of David Wiggins (1980) in particular, we can follow suit in formulating such a thesis as follows:

Wiggins' Thesis: for any biological organism, $o$, and any biological species, $s$, if $o$ is a member of $s$ (or 'part of s' if species are themselves individuals), then $o$ is essentially a member of $s$.

Biological organisms are essentially members of their biological species; it is metaphysically impossible for them to exist and thereby fail to be a member of the species to which they belong. Hence, Aristotle could not have been an aardvark and a turnip could not have been a tiger.

Despite its prima facie appeal, LaPorte and Okasha take aim at WIGGINs' THESIS on the grounds that such a view is empirically untenable in so far as every dominant species concept on offer entails its denial. Whether we adopt an interbreeding, ecological, or phylogenetic account of species, it is possible that the organism in question could have belonged to a different species than the one to which it in fact belongs.

To illustrate, they ask us to consider a single large population $(p)$ from which a small splinter group $(s)$ becomes physically isolated. Suppose that over time $s$ adapts to new environmental conditions and, as a result, diverges from $p$ such that interbreeding between the two populations breaks down. According to the interbreeding species concept, the members of $p$ and the members of $s$ would thereby constitute two distinct species, call them $s_{1}$ and $s_{2}$ respectively. But, they argue, since it is both possible that $s$ remain within $p$ and that $s$ might not have become reproductively isolated from $p$, it follows that any organism in $s$ might not have belonged to $s_{2}$ but, rather, may have belonged to $s_{1} \cdot{ }^{3}$

The argument, claims LaPorte and Okasha, can be generalized to ecological and phylogenetic species concepts as well, LaPorte (2009: 59) going so far as to say that "every account [of species] that so much as allows for the possibility of evolution, as all mainstream professional accounts on the market do, also allows for the possibility that organisms do not essentially belong to their respective species." As a result, an organism's biological species is

\footnotetext{
${ }^{2}$ It is important to note the distinction between what I am calling " $d e$ re biological essentialism"- essentialism about individual biological organisms-and essentialism about biological kinds. As stated, the topic of this note is the former.

${ }^{3}$ LaPorte (2009: 57) and Okasha (2002: 205-206).
} 
not essential to it and hence Wiggins' Thesis is empirically untenable, despite its being adhered to by a wide number of contemporary metaphysicians who register support for de re essentialism.

Suppose we grant that the argument is capable of being generalized to every major species concept on offer in the literature (as well as those species concepts that allow even for the mere possibility of evolution), what then of Wiggins' Thesis? The argument trades on a de re/de dicto modal ambiguity. LaPorte and Okasha reason as follows:

(E1) It is possible that $s$ remain within $p$.

(E2) If it is possible that $s$ remain within $p$, then it is possible that the members of $s_{2}$ belong to $s_{1}$.

Therefore:

(E3) It is possible that the members of $s_{2}$ belong to $s_{1}$.

Which they take to undermine the truth of Wiggins' Thesis in that:

(E4) The members of $s_{2}$ are not essentially members of $s_{2}$.

As it stands, E4 is a de re claim concerning the individual members of $s_{2}$ and is the denial of the essentialist's notion of species-membership captured by Wiggins' Thesis. E3, however, is a de dicto claim stating that the proposition <that the members of $s_{2}$ belong to $s_{1}>$ is possible. It is a claim, we might add, that the de re biological essentialist need in no way be threatened by; the proposition <that the members of $s_{2}$ belong to $s_{1}>$ is certainly not necessarily true in so far as the branching of $s$ and $p$ could have failed to obtain.

Hence in order to infer the falsity of Wiggins' Thesis from E3, LaPorte and Okasha need the following de re reading of E3:

$(\mathrm{E} 3 *)$ The members of $s_{2}$ could have belonged to $s_{1}$.

But not only does E3* not follow from the conjunction of E1 and E2, considered as a de re claim regarding species-membership, no essentialist worth their salt would grant the truth of E3* precisely because it entails the denial of Wiggins' Thesis. In collapsing the de re/de dicto distinction in moving from E3 to E4, LaPorte and Okasha proceed as if there is no de re modal structure in the biological realm, the very thing they set out to undermine. As a result, Wiggins' Thesis remains unscathed.

LaPorte and Okasha's argument discredits "Wiggins' erroneous thesis" (Okasha 2002: 207) as being "embarrassingly at odds with current, mainstream systematics” (LaPorte 2009: 61) only by ignoring a long-standing 
distinction that has been at the very heart of contemporary modal metaphysics. ${ }^{4}$ While it goes without saying that metaphysicians do well to heed developments in modern biology, one may well suspect that this oft repeated line of reasoning against the application of de re essentialism to the biological domain may find a more natural explanation in (ii) than is often recognized.

\section{References}

[1] LaPorte, Joseph. 1997. “Essential Membership.” Philosophy of Science 64, 96-112.

[2] LaPorte, Joseph. 2009. Natural Kinds and Conceptual Change. Cambridge University Press.

[3] Okasha, Samir. 2002. "Darwinian Metaphysics: Species and the Question of Essentialism.” Synthese 131: 191-213.

[4] Plantinga, Alvin. 1974. The Nature of Necessity. Oxford: Clarendon Press.

[5] Wiggins, David. 1980. Sameness and Substance. Harvard University Press: Cambridge.

\footnotetext{
${ }^{4}$ See Plantinga (1974: 18-26).
} 